\title{
Business Advisory: A Study on Selected Micro-sized SMEs in Kelantan, Malaysia
}

\author{
Mohd Nor Hakimin Bin Yusoff \\ Faculty of Entrepreneurship and Business, Universiti Malaysia Kelantan \\ Locked Bag 36, Pengkalan Chepa, 16100 Kota Bharu, Kelantan, Malaysia \\ Tel: 60-9-771-7264 E-mail: hakimin@umk.edu.my
}

Mohd Rafi Bin Yaacob

Faculty of Entrepreneurship and Business, Universiti Malaysia Kelantan

Locked Bag 36, Pengkalan Chepa, 16100 Kota Bharu, Kelantan, Malaysia

Tel: 60-9-771-7265Ｅ-mail: rafi@umk.edu.my

Mohamed Dahlan Bin Ibrahim

Faculty of Entrepreneurship and Business, Universiti Malaysia Kelantan

Locked Bag 36, Pengkalan Chepa, 16100 Kota Bharu, Kelantan, Malaysia

Tel: 60-9-771-7200Ｅ-mail: dahlan@umk.edu.my

\begin{abstract}
This study seeks to investigate the business advisory awareness among some micro-sized SMEs in Kelantan, Malaysia, focusing on the advisory services supplied by various government agencies. Micro-sized SMEs were the centre of the study because they represent a large number of SMEs in the country. Notwithstanding with the various advisory services provided by the government agencies in the state, result of the study showed the majority of respondents was not fully aware of and assured on the existence of business advisory services. Furthermore, the results of the study indicated no significant relationship between all the demographic factors of businesses and the level of awareness of business advisory among micro-sized SMEs. The key findings of the study are instructive. Actions should be taken by the government and its relevant agencies to enhance the level of awareness and knowledge of the importance of advisory among micro-sized SMEs. It seemed that the information pertaining to the business advisory services are not well disseminated to the targeted group. This failure distorts the government plan to efficiently support SMEs, thus leading to waste of scarce resources. Suggestions were also made to significantly address these issues.
\end{abstract}

Keywords: Business advisory, Awareness, Micro-sized SMEs, Kelantan, Malaysia

\section{Background of the study}

In a competitive business environment, enterprises that utilise business advisory services effectively, experienced a higher growth compares to others who did not (Berry and Sweating, 2006; Butker and Durkin, 1998). Considering the significant roles of Small Medium Enterprises (SMEs) to the economic growth, the government has provided numerous business advisory services through various agencies to support the SMEs' activities. For example, Majlis Amanah Rakyat (MARA) among others offers services such as financial assistance (loan), training and infrastructure facilities. Nevertheless, the utilisation of the government support and advisory services among SMEs in particular micro-sized SMEs, is considered very low (Ramsden \& Bennet, 2005; Matton, 1999 cited in Devin et, al 2005). There are number of questions related to utilisation of business advisory services in the country: Do micro-sized SMEs effectively utilised the advisory services provided by relevant government agencies? Are they aware of the existence of the business advisory services offered by the government support agencies? In order to answer these questions, the present study looks at the level of awareness on the existence of business advisory services supplied by the government agencies among micro-sized SMEs, focusing on entrepreneurs under the supervision of one of the micro credit agency. In addition, it will also verify whether selected demographic factors have positive relationship with the level of awareness of micro-sized SMEs. Based on the findings, the present study proposes actions to be taken by the relevant government agencies in order to improve the awareness and usage of the advisory services among micro-sized SMEs. 
The government of Malaysia in order to enhance the effectiveness of advisory services has classified SMEs into 3 categories which based on the annual sales revenue and number of full time employees. Enterprises with annual sales revenue of less than RM25 million and number of employees less than 150 are categorised as SMEs. SMEs are further classified based on activities; services (including ICT) and manufacturing (including agro-based industries) and to its size namely; micro, small and medium as shown in Table 1.

Businesses with sales revenue of less than RM250, 000 a year and number of employees less than 5 is categorised under micro-sized enterprises. This study focus on this group to measure the level of awareness on the existence of business advisory by government support agencies. Generally speaking, SMEs are known to operate under limited resources, thus, experiencing low productivity and less efficient in their daily activities. Lack of capital and skilled human resources are common disadvantages faces by SMEs. The low capital hinders SMEs to recruit high skilled employees or graduates. The SMEs in particular micro-sized SMEs can't afford to pay the skilled employees equivalent to the market rate. Beside that, SMEs are often facing problems to compete with large enterprises due to lack of business experience, access to resources, financial strength and technologies (Mendoza and Gilberto, 2004). Knowing the weaknesses faced by SMEs, the business support services which range from financing to expansion of business are relevant throughout the tenure of the business (Gunasekaran, Forker and Kobu, 2000).

Thus, the significance of this study comes under a number of perspectives. Firstly, the input of this study provides a guide for advisory providers to further enhance the information delivery system to the targeted group. Secondly, the findings can be used by service providers to develop suitable programmes to increase the level of awareness and knowledge of the targeted groups. Finally, by further expand the programmes it will improve the utilisation of the services, thus it will increase the efficiency and avoid unnecessary waste of scarce resources.

\section{Literature review}

\section{Definition of business advisory services}

Schaper and Volley, 2001 cited in Jay and Schaper (2003) defined business advisor as; “...someone who provides specialised skill and knowledge in one or more particular aspects of business operations".

Business advisor is a person or party with the capacity to give input to the business owner for enhancement of growth and betterment of the client operations. Business advisors may also act as mentor to small business operators in managing the operating unit of their businesses. Berry and Sweating (2006) argued that in general, business advisers sell the new ideas to SMEs owner-managers for them to implement in their respective businesses. The sources of business advisory services usually come from government which is non-commercial in nature, and private consultants that offer their services for commercial gain. Both parties provide wide range of services to support the small business owner. In essence, business advisory services must be able to support the small business operators by providing assistance to overcome the constraints such as lack of skills, knowledge and financial management.

\section{The essentials of business advisory}

The dynamic nature of business environment has created great challenges to miro-sized SMEs. Being micro in size, they are operating with inadequate capital and less skilled human resources thus leaving the entrepreneur to run their business in inefficient manner. As a matter of fact, SMEs greatly need external supports to fully exploit their potentials (Caniels and Romjin, 2005). The experts' assistance is deemed significant to promote SMEs' business growth, so that they will remain competitive in the market. Businesses that frequently seek advice have experienced positive impacts on the business performance (Berry and Sweating, 2006). Shepherd and Wiklund (2005) found that a regular contact with government support agencies resulted in favourable influences on the growth of the micro-sized business. Considering micro-sized business, there are always restriction to access the resources and weak internal planning as well. Thus, the need for external support and advice becomes greatly important and essential to the survival of SMEs.

\section{The role of the Malaysian government in supporting SMEs}

In Malaysia, the government participation in supporting SMEs was started before the Independence Day 1957. The activities begin with the establishment of Rural Industry Development Authority (RIDA) in 1950. The main objective of RIDA was to enhance economic activities among rural folks. The vigorous business advisory activities started in 1970 under New Economic Policy (NEP) where various government agencies have been set up to assist SMEs. NEP was a 20 years long term plan with main objectives to eradicate poverty among Bumiputra and socio-economic restructuring among races. The active government involvement in developing SMEs was continued in the second Industrial Master Plan (IMP2) and third Industrial Master Plan (IMP3) which 
ends in 2005 and 2020 respectively. Over the years the government has spent a huge amount of money to advisory programmes in line with objectives to support the business activities of SMEs. In 2007 and 2008 the government has spent RM4.9 billion and RM3 billion respectively in forms of training and financial programs among others. The programs were channelled via various relevant agencies (SMIDEC Annual Report, 2008). The huge amount of money shows the government commitment to ensure the continuity of SMEs' business activities in challenging business environment. In Malaysia the business advisory services are formally provided by both government and private sectors. There are more than 25 government agencies and statutory bodies offering the services (www.smeinfo.com.my, accessed on 12 October 2009). The business advisory services offered can be classified into four main types namely; financial facilities, management training programs, technical training programs and business consultancy.

\section{Micro-sized business awareness of advisory services}

Previous studies have shown that numbers of the business advisory services sponsored by government are not fully utilised (Boter and Lundstrom, 2005; Berry and Sweating, 2006; Curan, 2000; Imran, 2009). Mismatch of the services provided in terms of content and entrepreneurial factors among the reasons cited for the low usage (Curan, 2000). Other reasons were due to poor formulation, implementation, evaluation, and control of the support programmes (Pilgrim and Meier, 1994 cited in Khairudin, 2007). In another study by Berry and Sweating (2006) in the UK, they found that six parties were identified as sources of business advice namely; accountant, banks, business networking, government agencies, friends and academicians. Of those, government agencies were ranked as the third preferred by SMEs for the sources of advice. Accountants were the most preferred followed by banks, business networking and academicians. They argued that government agencies were perceived as providing inefficient services turn into unpopular among SMEs. Furthermore, SMEs were not convinced by the officer in-charge since they were perceived as incapable to perform their duties as advisors. However, the above study does not measure the awareness of respondents pertaining to business advisory services. A similar study in Australia indicated that government support programmes were not the main choice for SMEs (Jay and Schaper, 2003). The utilisation rate on the services provided was far beyond satisfactory. Accountant as the most popular source of advice compare to other sources were also found in New Zealand business environment (Lewis et al., 2007).

Majority of SMEs were not aware of the services provided by government (Khairudin, 2007; Oc and Tisdell, 1999: Ram and Jones, 1998 cited in Emslie and Bent, 2007). Those studies reported that only $15 \%$ to $20 \%$ of the SMEs make use of the services. Furthermore, the low level of awareness was one of the factors contributing to the poor usage of the government advisory services. Various studies in developed countries also showed that only less than half of the SMEs utilised the services provided by government support agencies or government funded program (Berry and Sweating, 2006; Bennet and Robson, 1999). This phenomenon is also related to the level of awareness on such services. A significant number of micro-sized SMEs in particular were unaware about the availability of advisory services to support their business activities supplied by the relevant government agencies (Emslie and Bent, 2007. Furthermore, the study conducted by SMIDEC (2002) reported that lack of knowledge and information was among issues affecting SMEs operation. The tendency to acquire information for operation improvement is low among local SMEs. A study by Khairudin (2007) on local credit guarantee agency in Malaysia found that only $10.1 \%$ of the respondents were aware of the support services provided. This finding was supported by study conducted by Foziah, Aziz and Sudin (2006) which point out the low utilisation of the government financial assistance among SMEs in northern Peninsular Malaysia. The low level of awareness about the services and bureaucracy were identified to be factors for the low utilisation of ther services. The under utilisation is compounded when the entrepreneurs perceived financial support program is the only advisory services provided by government (Hakimin, 2009). Based on the literature, lack of knowledge and limited resources are among the barriers for the micro-sized entrepreneurs to access the information about the government advisory services other than financial support or funding. As a result, the advisory related to technical, marketing and management were ineffectively used. From the above literature, the first hypothesis was developed:

\section{H1: Micro-sized business owners unaware of the existence of the business advisory services.}

To measure the relationship between the level of awareness and demographic factors of micro-sized SMEs, a number of demographic variables were selected. The first variable selected was age of the owner. One might say that, the older of a person the wiser he/she. The older the managers, the better performance they are as compare to the young managers because they have more business experiences. However, based on the study conducted by Srivastava and Lee (2008), it shows that the age of top management teams has no relationship with the firms performance. The study by Morales and Marquina (2008) also shows that age of employees was not significantly 
vary with the perception team performance. However, in terms of utilisation of business advisory, a study by Jay and Schaper (2003), shows that the older of the age the more the owner seeks the advice from those who knowledgeable in business. Both studies disclosed a contradiction of the two different views of advisory between utilisation of advice and firms performance vis-a-vis to age of the management. While performance has no relationship with age of employees, the tendency to seek more advice more on older management. This disagreement forms the basis of the second hypothesis;

$\mathrm{H} 2$ : The age of the owners has no correlations with the level of awareness of the existence of business advisory services.

The second variable was age of the business. The age of buisness has relationship with the need of the external support. As the business goes along the cycle, the demand for external assistance is more (Wu, Song and Zeng, 2008). Usually, business need more capital and other supports to brace expansion. A study by Jay and Schaper (2003) also indicates that the longer the business has been established the more its owner uses the advisory services. As a result, age of the business related to the need of the advisory's services. Based on the existing literature, the following hypothesis was developed;

H3: The age of the business correlates positively with the level of awareness of the existence of business advisory services.

The third variable was related to business income or sales generated. Sales can be used as one of the growth indicators (Wiklund and Shepherd, 2003; Barringer, Jones and Neubaum, 2005). The frequency of utilisation of business advisory has positive correlation with the growth of the SMEs' business (Berry and Sweating, 2006; Butker and Durkin, 1998). In predicting the level of awareness about the government business advisory services, the business income was selected as gowth indicator in present study. The income level reflects the frequency of advisory utilised by micro-sized SMEs, those with more income level were more aware about the services vis-a-vis those in less income bracket. Hence, $r$ the following hypothesis was developed;

H4: Business income has relationship with he level of awareness of the existence of business advisory services.

\section{Research Methodology}

The model of the present study is based on the previous study conducted in Australia which verified a significant relationship exist between owners' age, age of the business and number of workers and the usage of business advice (Jay and Schaper, 2003). They found that the longer the business has been established, the more its owner uses the advice. Similar relationship was found with regard to the age of the owner. It also found that the more employees employed the more advice was used. As for the current research, some modifications have been made to the earlier model developed by Jay and Schaper (2003) in Australia. While Jay and Schaper (2003) used number of employees, this study uses income to represent growth as the difference amongst number of employees of micro-sized businesses is not significant. The highest number of employees employed was 6-10 person (7\%) and most of entrepreneurs are owner/manager and do not have any employees. The result showed that $93 \%$ of the respondents have $0-5$ person of employees.

This study used closed ended questionnaires survey to measure the level of awareness on the existence of business advisory services provided by government agencies. The constructs of the questionnaires were designed based on the results of the preliminary interviews conducted with two officers from one of development financial institutions in Kelantan. Further information from literature review were also used (Khairudin, 2007, Berry \& Sweating, 2006; Jay and Schaper, 2003; Lange, Othens and Taylor, 2000). Late July 2009, 95 sets of self-administered questions were distributed among micro-sized SMEs who attended a motivation course. Figure 1 shows type of businesses run by respondents.

As far as type of businesses are concerned, $36 \%$ of respondents involve in food based business, $33.7 \%$ carry out groceries store, small contractors and petty traders. Others are those involved in trading of textile (11.6\%), garments $(4.6 \%)$, furniture (3\%) and agro-based product (1.1\%). Most of business activities operated in small scale of capital, and some of them run their business at home. The reliability test was performed using Cronbach Alpha, with a cutting point of $60 \%$ (Nunally, 1978). The result of reliability test shows that the level of reliability for all constructs of advisory are more than $80 \%$, except for expansion of business which is $55 \%$. Hence, this construct was dropped since the test on "if item deleted" did not change much on the value of Cronbach Alpha. The reliability tests were performed after all the data were cleaned and edited to increase the validity of the data. In addition, the result of K-S test indicated that all data are normal at $\mathrm{p}>0.05$.

\section{Findings and discussion}

Demographic information 
Of 95 respondents, $44.6 \%$ aged of between 41 to 50 which represent the largest proportion, and $29.3 \%$ aged between 31 to 40 years old, $15.2 \%$ more than 50 years old and the least less than 30 years $(10.9 \%) .77 .9 \%$ respondents obtained only secondary school qualifications, $4 \%$ with diploma, $1.1 \%$ master and $8.4 \%$ primary school. A total of $70.5 \%$ of the respondents operated businesses on full-time basis and the rest $27.5 \%$ operated on part-time basis. This indicates that some of the businesses are run along with other economic activities, thus, entrepreneurs were not fully committed on the business activities. The demographic information is shown in Table 2.

In terms of business registration, $83.2 \%$ of respondents run the businesses as sole-proprietorship, $8.4 \%$ as private limited company, $3.2 \%$ partnership and $2.1 \%$ in the process of registering the business as sole proprietorship (Figure 2). The results indicate that majority of respondents operating simple small scale business having low entry barrier. This is in line with the selection of respondents who fall under micro-sized SMEs. All respondents operate with low amount of capital where $78.9 \%$ hold capital of less than RM10, 000 and only $1.1 \%$ holds capital of more than RM200,000.

Looking at the sales revenue shown in Figure 3, 47.7\% of the respondents' business earned less than RM10 thousand a year, $39.8 \%$ more than RM11 thousand but less than RM50 thousand. Only 3.4\% enjoyed the revenue of more than RM250 thousand a year but less than RM500 thousand. This finding indicates that majority of respondents earned a tiny amount of revenue on average of RM800 a month.

\section{Awareness on the business advisory services}

H1: Micro-sized business owners aware of the existence of the business advisory services.

The constructs to measure the level of awareness were developed in order to measure the knowledge of business advice pertaining product quality, technical, marketing and management/administration. Five point Likert scale ranging from 1 disagree, to 5 strongly agree was used as measurement of the construct. The results of mean value and one sample t-test of each construct are shown in Table 3 and 4. Overall, the result indicates that the majority of respondents were not fully aware of and assured on the existence of business advisory services. The advisory's role on the improvement quality of product is the highest mean (3.31). On the other hand, the lowest is the support for management/administration (3.01). Other means - management and marketing are sandwiched between both constructs.

Not withstanding with the role of advisory to enhance product quality and management of businesses, this finding indicates that respondents were not certain on the benefit of services offered by the relevant government agencies. They might know about the marketing supports in general but, in doubt of the other assistance offered. For instance, some of the micro-sized SMEs are not aware about spaces provided by government agencies for selling their product. This finding also corresponds to the researcher's experience who dealt with micro-sized entrepreneurs during his past employment with a financial institution. Often, entrepreneurs are shock and amaze on the availability of support services offered by agencies. They usually unaware of the numbers of facilities and programmes designed to support their activities. For instance, they are unaware of the existence of financial facilities in form of grants to enhance the business activities by number of government agencies. Thus, it is not surprising for that facilities were said to be under-utilised. It is believed that information pertaining to the advisory services does not reach the targeted group as they were not properly disseminated. The findings also indicated that most of the entrepreneurs don't even know that apart from financial institutions and micro financial providers, there are government agencies such as MARDI, FAMA, MARTRADE and KADA (to name out a few) that provide advisory services for small and micro sized businesses. In conclusion, the level of awarness of the availability of the services among respondents is considered very low.

To test the differences between the sample means and the hypothesised mean, univariate technique was used one-sample t-test. Test value (hypothesised mean) is set at 4 which indicate "agree" for each sample mean. The results showed that there are significant difference between the hypothesised mean and sample mean, with value of its two-tail significance at 0.001 levels. It shows that majority of respondents are not fully "agree" and in doubt about the existence of business advisory services mean sample ranging from 3.10 to 3.31 which falls under partly agree. Therefore, the hypothesis $\mathrm{H} 1$ is rejected.

\section{Demographic and level of awareness}

Age

H2: The age of the owners correlates positively with the level of awareness of the existence of business advisory services 
The finding shows that no significant relationship exist between age and awareness of the respondents. This is quite surprising, since majority of respondents $(46 \%)$ is in the 'maturity' cohort (30 - 50 year). However, the level of knowledge and awareness on the relevant variables to the business is still low. It seemed that age is not a factor of influence to the level awareness on the advisory services among micro-sized SMEs. On the contrary, previous study in Australia have shown that the older the owner the more frequent they used advisory services, which manifested the respondents' high level of awareness (Jay and Schaper, 2005). In Australia, the information with regards to advisory services was well disseminated to the targeted group. Hence, most of the entrepreneurs were aware of such services and make use of them appropriately.

Moreover, in a study in the UK by Shepherd and Wiklund (2005) found that a person with better educational background could have better social network to obtain the resources to achieving goals. It is argued that education plays vital role in supporting business growth. $86 \%$ of the respondents in this study have no higher educational background and run business as owner/manager. The respondents' level of awareness of the advisory services was found to be low. The result supports the finding by Shepherd and Wiklund (2005).

No cross tabulation analysis is performed between education and level of awareness of advisory services in this study since majority of the respondents have similar educational background. It is believed that the level of awareness may have relationship with education background. Furthermore, most of the entrepreneurs of micro-sized business in Kelantan are owners/managers, single operator and trapped with time constraints. Hence, less time is allocated for planning and related activities for their future business growth. As a result, the usage of business advisory services are low owing to the availability of the services is not known. This study also revealed that $85 \%$ of the respondents have experience with the financial support services, however none of the respondents have used marketing and technical advisory services. One possible reason is that they are not aware of the availability of the services other than financial assistance. Therefore, micro-sized SMEs continuously run the businesses with least external assistance in particular from the government agencies.

Furthermore, it is also believed that level of education may also influence the level of awareness which associated to the propensity to seek advice from the government agencies. Much of the earlier literature discussed about the vulnerability of SMEs. Hence, they need external resources especially from government agencies to support the business growth. However, majority of the respondents were from low educational background, thus the low level of knowledge leads to the low awareness of the advisory services. In conclusion, age has no significant effect to influence the level of awareness among micro-sized SMEs. Observation from the four chi-square test of the constructs found that no significant difference between age of the respondents and the level of awareness of the business advisory services $-p>0.05$ (Table 5). As the finding suggest, $\mathrm{H} 2$ is rejected.

Age of business

H3: The age of the business correlates positively with the level of awareness of the existence of business advisory services.

Logically, the longer a person involves in business, the larger network and contact is established, and more information about the business support is obtained. However, the finding shows that the tenure of business has no significant relationship on the level of awareness of the advisory services among respondents. Observation from the four chi-square indicates that no significant difference $-p>0.05$, except for 2 variables which show a significant relationship with tenure of business; processing technique $(p=0.031, p<0.05)$ and marketing advise in general $(\mathrm{p}=0.050, \mathrm{p}<0.05)$.

The awareness of availability of advisory on processing technique has a significant relationship with the tenure of business. It shows that the longer of the business in establishment the higher level of awareness on processing technique. Why there are no significant difference between the variables of machineries information and raw material \& supplier and the level of awareness? One possible explanation is that most of the respondents' business does not involve machineries, high technology equipment, and consumption of a scarce raw material. The operation of business is simple with uncomplicated processing. But as business operates over time they might be exposed to the technical information, especially the enhancement of processing technique. As a result, the respondents should be fairly aware of the availability of such services. In addition, they do not give a great worry on those two variables as both are not highly relevant to their current business activities.

As indicated in the Table 6, marketing advisory awareness also has significant relationship with the age of business. This is the first question in the marketing construct that intend to measure the respondents' knowledge about the marketing services. Supposedly, the longer the business is established the higher the level of awareness on the marketing advisory services provided by government. However, it did not show in the other 3 variables under the same construct which outlined the details of the services under marketing advisory. All the other 3 
variables have no significant relationship with the age of the business. This result indicates that, respondents know and notice about the existence of marketing advisory services but they are not sure about the programs in detail. Majority of the micro-sized SMEs assumed marketing is merely selling off the products and nothing to do with the issues of pricing, distribution and promotion. Therefore, the advisory services are under-utilised and some are not sought for. The data in this study confirmed that respondents are aware about marketing advisory services but with limited knowledge. They run their businesses without a great concern on the environment that may influence their business activities. Surprisingly, there are respondents with more than 10 years of business establishment and yet lacking on the awareness of the availability of the advisory services. Finally, based on the observation of chi-square of four construct, it is found that no significant difference between age of business and level of awareness of advisory services among micro-sized SMEs ( $p>0.05)$. Thus, H3 is rejected.

Income

H4: The higher the business income, the higher is the level of awareness of the existence of business advisory services.

This section describes the relationship between income and the level of awareness. The level of income or sales is one of the indicators to the growth of the business (Brian and Storey, 2006). The finding shows that, the growth of the respondents' businesses was not influenced by the government's advisory services. As indicated in previous findings, respondents were independent and operate the business with minimum external assistance.

Table 7 presents the result of cross tabulation between the business income and the level of awareness of different support services. All constructs have no significant relationship with respondents' income ( $\mathrm{p}>$ 0.05).The result indicates that the income generated is solely the entrepreneurs' effort and are not influenced by external supports, in particular business advisory services by the government agencies. The respondents are independent and no external advisory are used to support the business growth as they are unaware of the services. As mentioned earlier, the respondents' educational background may play important role to motivate the search of information pertaining to business advisory. The respondents with better education look forward for growth and have higher propensity to explore new business entry and venture compare to low education background (Shepherd and Wiklund, 2005).

In spite of the under utilisation of business supports, $34.8 \%$ of the respondents earned less than RM10 thousand a year, the average of RM800 a month, although they are operating the businesses on a full time basis. The meagre income shows the inefficiency of micro-sized SMEs in doing the business. The low level of income also justifies the implication of the absence of advisory services very much retards the respondents' business growth. The percentage of respondents with low income level is significant (34.8\%) and appeal for action to rectify it.

\section{Conclusion and Suggestions}

As far as this research is concerned, the low level of awareness among micro-sized SMEs in Kelantan, Malaysia demands a radical action to reform the delivery system of information pertaining to business advisory services. With regard to their size, the role of micro-sized SMEs are equal to other SMEs (small and medium) whereby they should not be discriminated and deserve the benefits and facilities provided by government. With a number of disadvantages in term of capital, human resource, skill, managerial know-how and being an owner/manager of business prevented them to access the available support pertaining to the advisory services. This handicap is further compounded as they are very busy with their daily operations which demand full concentration. As a result, they are not assured about the support services available for their business. It does not come as a surprise after many years in operation their businesses are still not productive, inefficient and slow in growth. Failure to fully capitalise the government support services may distract the government objective to develop a prosperous and dynamic entrepreneurial society in the country. The phenomenon has surfaced the failure of marketing and promoting the services. Arguably, according to Oc and Tiesdell (1999), low take-up rate of the advisory services provided by the government resulted from the failure of marketing on the part of the service providers.

\section{Recommendations}

This study reveals significant findings on the level of awareness among micro-sized SMEs in Kelantan, Malaysia which connote the inefficiency of advisory programmes in terms of delivery of information to targeted groups. Generally speaking, only a small proportion of the micro-sized SMEs are aware on the existence of such services. Having identified the level of knowledge on the business advisory services provided by government as well as the relationship between various demographic factors of business and advisory services, the following recommendations should be adopted by the government agencies; 
First, the government agencies pertaining to business advisory in Malaysia should reform their marketing programmes without considering any particular demographic background of the micro-sized SMEs. A low awareness of advisory services of government agencies warrants a right medium of information. However, choosing the best medium to increase level of awareness amongst micro-sized SMEs, it is necessary to conduct another study in the future.

Second, it is suggested that a more pro-active action should be taken by the service providers. It is the time for the relevant government agencies to take a fresh look and to identify what types of supports needed by SMEs. At the same time they also need to visit SMEs premises to disseminate the information pertaining to advisory services. Such a proactive approach could easily close the gap between SMEs and officers of service providers pertaining to advisory services.

Third, the government agencies should consider how to engage experienced and knowledgable officers to enhance the trust and reliability of services delivered to the targeted group (micro-sized SMEs). Coaching on the characteristic of micro-sized SMEs as well as their challenges would be imperative. Therefore the advisors have better understanding of the micro-sized SMEs characteristic and behaviour thus would enhance the effectiveness in dealing and identifying the needs of the business.

Fourth, since micro-sized SMEs rely more on their informal networking (friends) as source of information, the dessimation of information pertaining to advisory services via this channel would be effective. The establishment of peer group consist of reputable members of society belong the micro-sized SMEs is suggested. The government agencies in a periodical basis needs to conduct informal meeting with this group with the purpose to inform about services offered and latest development in the advisory activities. This action enable the information fastly delivered since all the peer members are socialize with the targetted groups.

\section{Future research}

The present findings draw to the following questions that warrant future research. First, does the business advisory providers fully utilise their resources to promote their services for efficiency of micro-sized SMEs? If the answer is no (considering the vital roles of micro-sized SMEs) the government need to review and develop internal programmes of the respective agencies to enhance the marketing of their services in order to increase the level of awareness among micro-sized SMEs. Such a strategy will increase the usage of advisory services. Second, how and from what channels micro-sized SMEs get the information pertaining to business advisory? Answer to the former question will provide the current scenario of practices of advisory providers in Malaysia. Such an investigation provides valuable information for future recommendations to improve their effectiveness and efficiency. In addition, answer of the latter question would be helpful to determine most popular channel for disseminating about advisory services amongst micro-sized SMEs. Hence, a more efficient advisory service could be efficiently delivered thus avoiding waste of scarce and valuable resources.

\section{References}

Barringer, B.R., Jones, F., and Neubaum, D.O. (2005). A quantitative content analysis of the characteristics of rapid-growth firms and their founders. Journal of Business Venturing, Vol. 20 No. 5, pp. 663-4.

Bennett, R.J., and Robson, P.J.A. (1999). The use of external business advice by SMEs in Britain. Entrepreneurship and Regional Development, Vol. 11 pp. 155-180.

Berry, A.J., and Sweating, R. (2006). The effect of business advice on the performance of SMEs. Journal of Small Business and Enterprise Development, Vol. 13 No. 1, pp. 33-47.

Boter, H., and Lundstrom, A. (2005). SME Perspectives on Business Support Services. Journal of Small Business and Enterprise Development, Vol. 12 No. 2, pp. 244-258.

Butler, P., and Durkin, M. (1998). Relationship intermediaries: Business advisers in the small-firm relationship. International Journal of Bank Marketing, Vol. 16, pp. 32-38.

Caniels, C.J., and Romijn, A.H. (2005). What works, and why, in business services provision for SME: Insights from Evolutionary Theory. Managing Service Quality, Vol. 15 No. 6, pp. 591-608.

Daily, C.M., and Dollinger, M.J. (1992). An empirical examination of ownership structure in family and professionally managed firms. Family Business Review, Vol. V No.2, pp.117-36.

Devins, D., Gold, J., Johnson, S., and Holden, R. A conceptual model of management learning in micro businesses. implications for research policy. Education + Training, Vol.47 No.8/9, pp. 540-551.

Emslie, L., and Bent, R. Public sector business support providers: Marketing business support to the ethnic business sector. Marketing Intelligence \& Planning, Vol. 25 No. 5, pp. 460-482. 
Foziah, I., Aziz, L., and Sudin, H. (2006). Entrepreneurs' awareness of bank borrowing offered by government agencies and commercial bank in Malaysia. Unpublished, 2006.

Gunasekaran, A., Forker, L., and Kobu, B. (2000). Improving operations performance in a small company: a case study. International Journal of Operations \& Production Management, Vol. 20 No. 3, pp. 316-335.

Jay, L., and Schaper, P. (2003). Which advisers do micro-firms use? Some Australian evidence. Journal of Small Business and Enterprise Development, Vol. 10 No. 2, pp. 136-143.

Khairudin, H. (2007). Small and medium-sized enterprises development in Malaysia: programs and evaluation. Universiti Utara Malaysia.

Lewis, K., Massey, C., Ashby, M., Coetzer, A., and Harris, C. (2007). Business assistance for SMEs: New Zealand owner-manager make their assessment. Journal of Small Business and Enterprise Development, Vol. 14 No. 4, pp. 551-66.

Mendoza, B., and Llanto, G. (2004). Government's role in developing entrepreneurship and SMEs in the Philippines. Entrepreneurship and SMEs in Southeast Asia, Institute of Southeast Asia Study, Singapore. pp.150-74.

Mohd Nor Hakimin Yusoff. (2009). Interview With SME Bank’s Officer. 10 Oktober, Kota Bharu.

Morales, C., and Marquina, P. (2009). Evidence on the role of age in team performance. A comparative study in Peru and Spain. Employee Relations, Vol. 31 No. 3, 2009, pp. 264-275.

Nunally, J.C. (1978). Psychometric theory ( $2^{\text {nd }}$ ed), New York, Mc-Graw Hill

Oc, T and Tiesdell, S. (1999). Supporting ethnic minority business: a review of business support for ethnic minorities in city challenge areas. Urban Studies, Vol.36 No. 10, pp 1723-46

Ramsden, M., and Bennet, R.J. (2005). The benefits of external support to SMEs. Journal of Small Business and Enterprise Development, Vol. 12 No. 2, pp. 227-243.

Shepherd, D. A., and Wiklund, J. (2005). Entrepreneurial small businesses. A Resource-Based perspective. Edward Elgar Publishing, pp 12-42, 43-76.

SME Annual Report 2008, National SME Development Council, Malaysia.

Srivastava, A., and Lee, H. (2008). Firm performance and top management team age, tenure and education: a research synthesis. International Journal of Business Research, [Online] Available: http://findarticles.com/p/articles retrieved on 10 February 2010.

Welsch, J. (1993). The impact of family ownership and involvement on the process of management succession. Family Business Review, Vol. VI No.1, pp.31-54.

Wiklund, L., and Shepherd, D. (2003). Aspiring for, and achieving growth: the moderating role of resources and opportunities. Journal of Management Studies, Vol. 40 No. 8, pp. 1919-41.

$\mathrm{Wu}$, J., Song, J., and Zeng, C. (2008). An empirical evidence of small business financing in China. Management Research News, Vol. 31 No. 12, pp. 959-975.

www.smeinfo.com.my

Table 1. Classification of SMEs in Malaysia

\begin{tabular}{|c|c|c|}
\hline \multicolumn{2}{|c|}{ Manufacturing (Including Agro-based) } & Services (Including ICT) \\
\hline Size & \multicolumn{2}{|c|}{ Annual Sales Revenue or No. of Full Time Employees } \\
\hline MEDIUM & $\begin{array}{l}\text { - } \quad>\text { RM10 mil -RM25 mil, or } \\
\text { - No. of full time employees: } 51-150\end{array}$ & $\begin{array}{l}\text { - } \quad>\text { RM1 mil -RM5 mil, or } \\
\text { - } \quad \text { No. of full time employees: } 51-150\end{array}$ \\
\hline SMALL & $\begin{array}{l}\text { - }>\text { RM0.25 mil -RM10 mil, or } \\
\text { - No. of full time employees: } 5 \text { - } 50\end{array}$ & $\begin{array}{l}\text { - } \quad>\text { RM0.2 mil -RM1 mil, or } \\
\text { - No. of full time employees: } 5-19\end{array}$ \\
\hline MICRO & $\begin{array}{l}\text { - }<\text { RM250,000, or } \\
\text { - No. of full time employees: }<5\end{array}$ & $\begin{array}{l}\text { - } \quad<\text { RM200,000, or } \\
\text { - } \quad \text { No of full time employees: }<5\end{array}$ \\
\hline
\end{tabular}

Source: The National SME Council, 2009 
Table 2. Respondents' Demographic Information

\begin{tabular}{|c|c|c|}
\hline Demographic & Frequency & $\%$ \\
\hline Age & & \\
\hline$<30$ & 10 & 10.9 \\
\hline $31-40$ & 27 & 29.3 \\
\hline $41-50$ & 41 & 44.6 \\
\hline$>50$ & 14 & 15.2 \\
\hline \multicolumn{3}{|l|}{ Education level } \\
\hline Master & 1 & 1.1 \\
\hline Degree & 0 & 0 \\
\hline Diploma & 7 & 7.4 \\
\hline Certificate & 4 & 4.2 \\
\hline Secondary School & 74 & 77.9 \\
\hline Primary School & 8 & 8.4 \\
\hline \multicolumn{3}{|l|}{ Involvement } \\
\hline Full time & 67 & 70.5 \\
\hline Part time & 26 & 27.4 \\
\hline \multicolumn{3}{|l|}{ Form of business } \\
\hline Sole proprietorship & 79 & 83.2 \\
\hline Private limited company & 8 & 8.4 \\
\hline Partnership & 3 & 3.2 \\
\hline Registration process & 2 & 2.1 \\
\hline \multicolumn{3}{|l|}{ Capital } \\
\hline$<\mathrm{RM} 10,000$ & 75 & 78.9 \\
\hline RM11,000 -RM50,000 & 8 & 8.4 \\
\hline RM51,000 - RM100,000 & 5 & 5.3 \\
\hline RM101,000 - RM200,000 & 2 & 2.1 \\
\hline RM201,000 - RM500,000 & 1 & 1.1 \\
\hline \multicolumn{3}{|l|}{ Revenue } \\
\hline$<\mathrm{RM} 10,000$ & 42 & 47.7 \\
\hline RM11,000 - RM50,000 & 35 & 39.8 \\
\hline RM51,000 - RM200,000 & 8 & 9.1 \\
\hline RM201,000 - RM500,000 & 3 & 3.4 \\
\hline
\end{tabular}

Table 3. Means of Business Advisory Services

\begin{tabular}{|l|c|c|c|c|}
\hline $\begin{array}{l}\text { Constructs of } \\
\text { Advisory Services }\end{array}$ & $\begin{array}{c}\text { No of } \\
\text { Respondent } \\
(\mathbf{n})\end{array}$ & $\begin{array}{c}\text { Mean } \\
\text { Value }\end{array}$ & sd & $\begin{array}{c}\text { One } \\
\text { Sample } \\
\text { t-test }(\boldsymbol{p})^{*}\end{array}$ \\
\hline Product quality & 92 & 3.31 & 0.994 & 0.001 \\
Management & 87 & 3.01 & 0.932 & 0.001 \\
Marketing & 89 & 3.04 & 0.997 & 0.001 \\
Technical & 93 & 3.02 & 1.035 & 0.001 \\
\hline
\end{tabular}

* test value $=4, p<0.05$

Table 4. One-Sample Test of Business Advisory Services

\begin{tabular}{|l|r|r|r|r|r|r|}
\hline & \multicolumn{2}{|c|}{} & \multicolumn{2}{|c|}{ Test Value $=4$} \\
& $\mathrm{~T}$ & $\mathrm{Df}$ & Sig. (2-tailed) & $\begin{array}{c}\text { Mean } \\
\text { Difference }\end{array}$ & \multicolumn{2}{c|}{$\begin{array}{c}\text { 95\% Confidence } \\
\text { Interval of the } \\
\text { Difference }\end{array}$} \\
\hline & & & & & Lower & Upper \\
\hline & -6.616 & 91 & .001 & -.6857 & -.8916 & -.4798 \\
Product Quality & -9.130 & 92 & .001 & -.9803 & -1.1935 & -.7670 \\
Mechnical & -9.031 & 88 & .001 & -.9551 & -1.1652 & -.7449 \\
Marketing & -8.742 & 86 & .001 & -.8736 & -1.0722 & -.6749 \\
\hline
\end{tabular}


Table 5. Age and Awareness of Business Advisory Services

\begin{tabular}{|l|c|c|c|}
\hline & \multicolumn{3}{|c|}{ Pearson Chi-Square } \\
\hline Construct & Value & Df & Asymp \\
& $\lambda^{2}$ & & Sig \\
\hline Quality Support Services & & & \\
Advisory services are provided by government & 19.191 & 12 & 0.084 \\
Product quality enhancement & 17.296 & 12 & 0.139 \\
Research on product improvement & 11.526 & 12 & 0.484 \\
Value added & 12.411 & 12 & 0.413 \\
\hline Technical Support & & & \\
Advisory services are provided by government & 17.66 & 12 & 0.126 \\
Information on machinery and equipment & 8.239 & 12 & 0.766 \\
Processing technique & 13.207 & 12 & 0.354 \\
Raw material and supplier & 11.539 & 12 & 0.479 \\
Marketing Support & & & \\
Advisory services are provided by government & 4.292 & 12 & 0.978 \\
Customers info & 9.633 & 12 & 0.648 \\
Pricing & 5.795 & 12 & 0.926 \\
Promotion & 5.186 & 12 & 0.951 \\
Management Support & & & \\
Advisory services are provided by government & 6.426 & 12 & 0.893 \\
Office management training & 14.428 & 12 & 0.274 \\
Documentation & 9.181 & 12 & 0.687 \\
Legal related & 14.697 & 12 & 0.258 \\
\hline
\end{tabular}

Table 6. Age of business and Awareness of Business Advisory Services

\begin{tabular}{|l|c|c|c|}
\hline & \multicolumn{3}{|c|}{ Pearson Chi-Square } \\
\hline Construct & Value & Df & $\begin{array}{c}\text { Asymp } \\
\text { Sig }\end{array}$ \\
\hline Quality Support Services & & & \\
Advisory services are provided by government & 10.91 & 16 & 0.814 \\
Product quality enhancement & 14.83 & 16 & 0.537 \\
Research on product improvement & 19.19 & 16 & 0.258 \\
Value added & 15.90 & 16 & 0.460 \\
Technical Support & & & \\
Advisory services are provided by government & 14.12 & 16 & 0.590 \\
Information on machinery and equipment & 18.05 & 16 & 0.321 \\
Processing technique & 28.09 & 16 & $0.031^{*}$ \\
Raw material and supplier & 21.74 & 16 & 0.152 \\
Marketing Support & & & \\
Advisory services are provided by government & 26.27 & 16 & $0.050^{*}$ \\
Customers info & 10.94 & 16 & 0.813 \\
Pricing & 13.23 & 16 & 0.656 \\
Promotion & 13.58 & 16 & 0.630 \\
Management Support & & & \\
Advisory services are provided by government & 14.25 & 16 & 0.580 \\
Office management training & 16.47 & 16 & 0.420 \\
Documentation & 13.39 & 16 & 0.640 \\
Legal related & 19.57 & 16 & 0.240 \\
\hline
\end{tabular}

*Significant at 0.05 
Table 7. Income and Awareness of Business Advisory Services

\begin{tabular}{|l|c|c|c|}
\hline & \multicolumn{3}{|c|}{ Pearson Chi-Square } \\
\hline Construct & Value & Df & $\begin{array}{c}\text { Asymp } \\
\text { Sig }\end{array}$ \\
\hline Quality Support Services & & & \\
Advisory services are provided by government & 10.93 & 12 & 0.535 \\
Product quality enhancement & 10.66 & 12 & 0.588 \\
Research on product improvement & 12.65 & 12 & 0.295 \\
Value added & 10.68 & 12 & 0.556 \\
Technical Support & & & \\
Advisory services are provided by government & 6.52 & 12 & 0.88 \\
Information on machinery and equipment & 4.97 & 12 & 0.959 \\
Processing technique & 4.74 & 12 & 0.966 \\
Raw material and supplier & 5.03 & 12 & 0.957 \\
Marketing Support & & & \\
Advisory services are provided by government & 7.21 & 12 & 0.843 \\
Customers info & 14.39 & 12 & 0.143 \\
Pricing & 10.64 & 12 & 0.560 \\
Promotion & 5.03 & 12 & 0.898 \\
Management Support & & & \\
Advisory services are provided by government & 11.55 & 12 & 0.483 \\
Office management training & 11.38 & 12 & 0.497 \\
Documentation & 10.79 & 12 & 0.547 \\
Legal related & 8.42 & 12 & 0.752 \\
\hline
\end{tabular}

Table 8. Income and Awareness of Business Advisory Services

\begin{tabular}{|l|c|c|c|}
\hline & & Pearson Chi-Square \\
\hline Construct & Value & Df & Sig \\
\hline Quality Support Services & & & \\
Advisory services are provided by government & 10.93 & 12 & 0.535 \\
Product quality enhancement & 10.66 & 12 & 0.588 \\
Research on product improvement & 12.65 & 12 & 0.295 \\
Value added & 10.68 & 12 & 0.556 \\
Technical Support & & & 0.88 \\
Advisory services are provided by government & 6.52 & 12 & 0.959 \\
Information on machinery and equipment & 4.97 & 12 & 0.966 \\
Processing technique & 4.74 & 12 & 0.957 \\
Raw material and supplier & 5.03 & 12 & 0.843 \\
Marketing Support & & & 0.143 \\
Advisory services are provided by government & 7.21 & 12 & 0.560 \\
Customers info & 14.39 & 12 & 0.898 \\
Pricing & 10.64 & 12 & 0.483 \\
Promotion & 5.03 & 12 & 0.497 \\
Management Support & & & 0.547 \\
Advisory services are provided by government & 11.55 & 12 & 0.752 \\
Office management training & 11.38 & 12 & 12 \\
Documentation & 10.79 & 12 & \\
Legal related & 8.42 & & \\
\hline
\end{tabular}




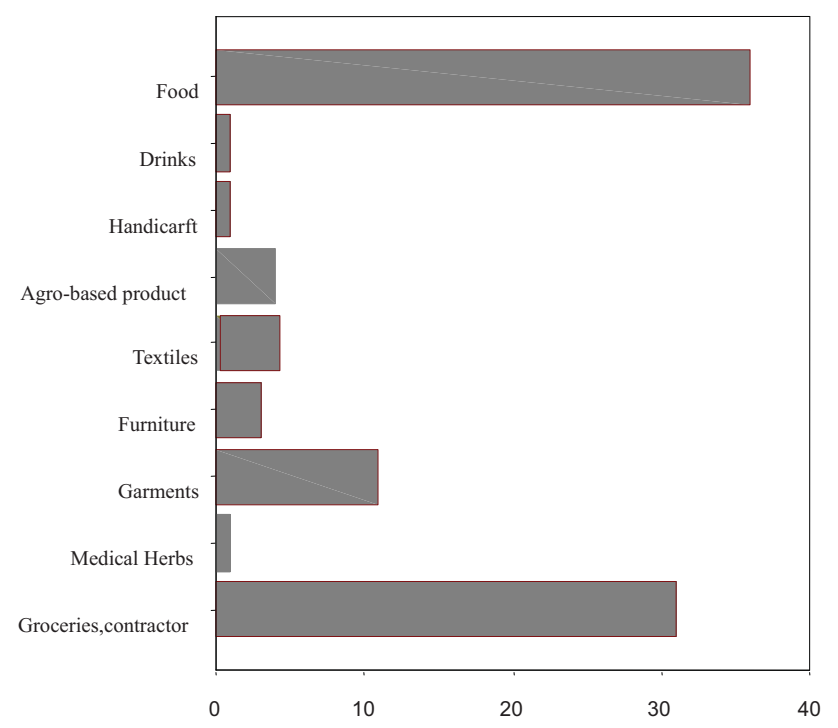

Figure 1. Respondents' Type of Business

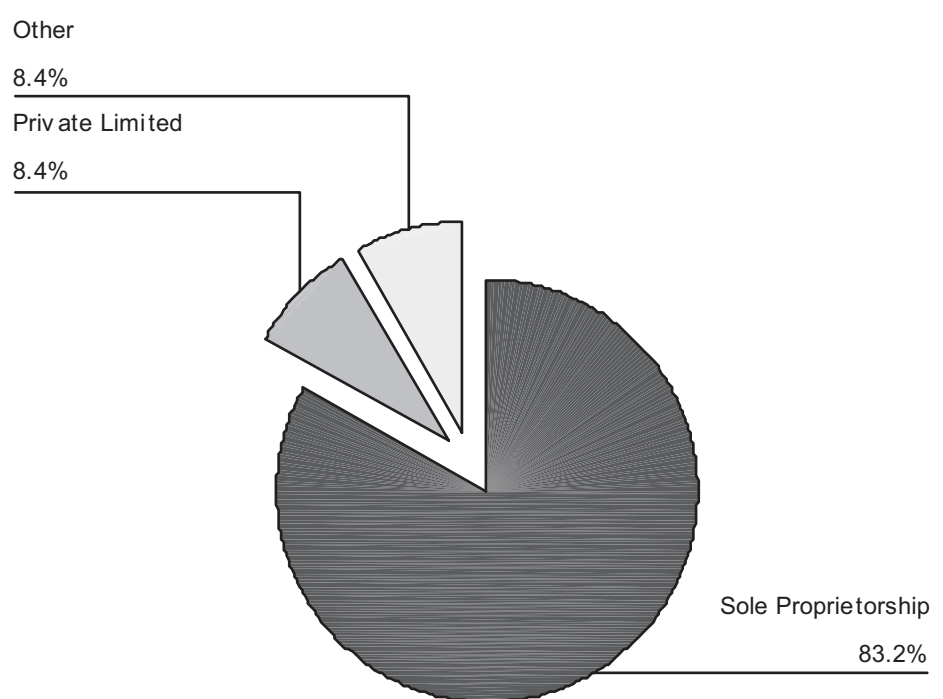

Figure 2. Respondents' Form of Business

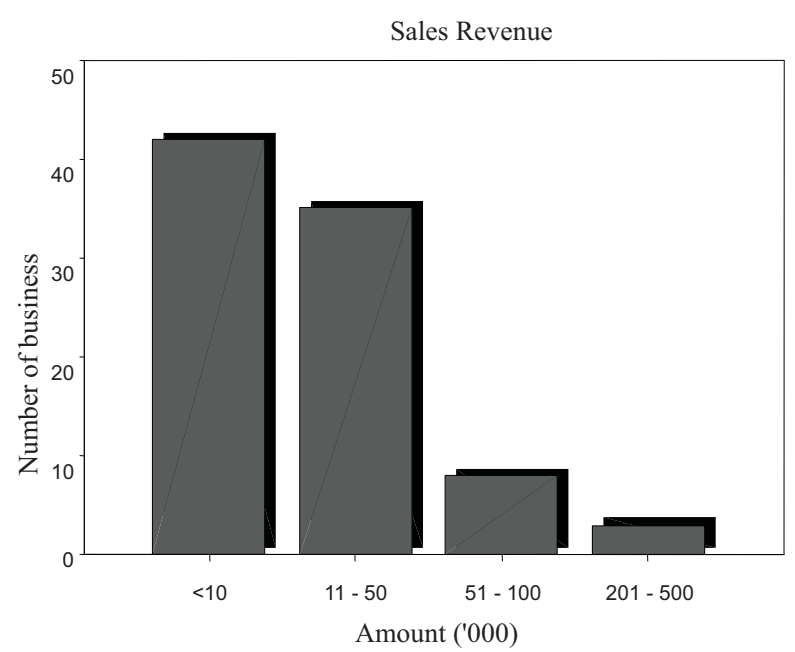

Figure 3. Yearly Revenue 